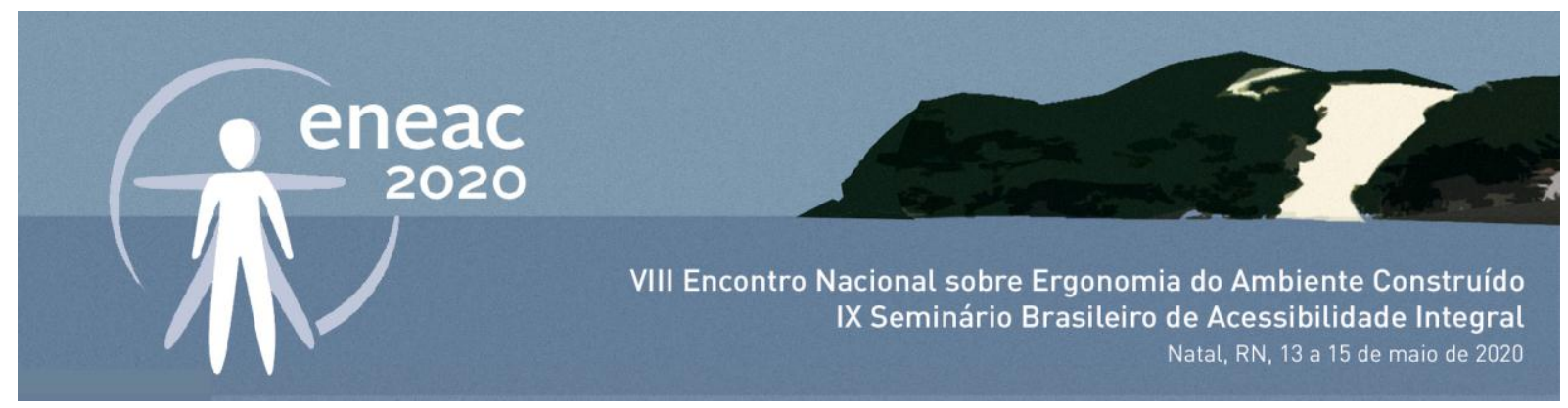

\title{
Hotéis acessiveis: estudo comparado em rede de hotéis nas cidades de Fortaleza, no Brasil e Lima, no Peru
}

\author{
Affordable hotels: a comparative study in a hotel chain in the cities of \\ Fortaleza, Brazil and Lima, Peru
}

ZILSA MARIA PINTO SANTIAGO

Doutora, PPGAUD/Universidade Federal do Ceará, zilsa@arquitetura.ufc.br

CARLOS BRUNO OLIVEIRA ROCHA

Graduando, Universidade Federal do Ceará, carlosoliveira@arquitetura.ufc.br

RENATA MELO ARAÚJO

Graduanda, Universidade Federal do Ceará, renatama_@arquitetura.ufc.br

SABRINA CAETANO DA SILVA

Graduanda, Universidade Federal do Ceará, sabrina_caetano_silva@hotmail.com

\section{RESUMO}

O turismo acessível se constitui uma questão de competência tanto das autoridades públicas, na sua promoção e fomento, como uma iniciativa dos agentes do setor - agências de viagens, operadores turísticos, fornecedores de transporte de traslados e passeios, gestores de alojamento - além de um compromisso coletivo, uma oportunidade de negócio e uma vantagem competitiva. O objetivo deste trabalho é fomentar o debate acerca do turismo acessível e verificar o nível em que se encontra a produção do ambiente construído, especificamente, em rede de hotéis, comparando um hotel no Brasil e um em outro país da América Latina, em face das exigências de um mundo diversificado. 0 trabalho se justifica por serem hotéis da mesma rede em cidades litorâneas porém de clima diferenciados. Como fundamentação teórica, buscou-se leitura de livros e artigos relacionados ao turismo e hotelaria (ALEXANDRE, 2013; SOUZA, 2015; VANZELLA et al, 2018; VARGAS \& PAIVA, 2016), além da pesquisa em fontes de dados oficiais (Ministério do Turismo, 2013;2018; Organização Mundial do Turismo). Para seleção dos critérios de análise, tomou-se como base princípios do Desenho Universal (PREISER, 2001; CAMBIAGHI, 2007) de forma a atenderem pré-requisitos necessários oferecendo condições de orientação - deslocamento - comunicação e uso (DISCHINGER et al, 2011), sem limitações e obstáculos. E como parâmetros as normas e leis de ambos países. A metodologia de campo utilizada nos hotéis de Fortaleza, teve como base a Avaliação Pós-Ocupação (ORNSTEIN, 1992; RHEINGANTZ et al., 2009) com ênfase na avaliação física. Tendo sido elaborado um checklist focado em funcionalidades de hotel para os levantamentos in loco com registro fotográfico. Os resultados foram positivos em relação aos elementos que favorecem a acessibilidade de pessoas 


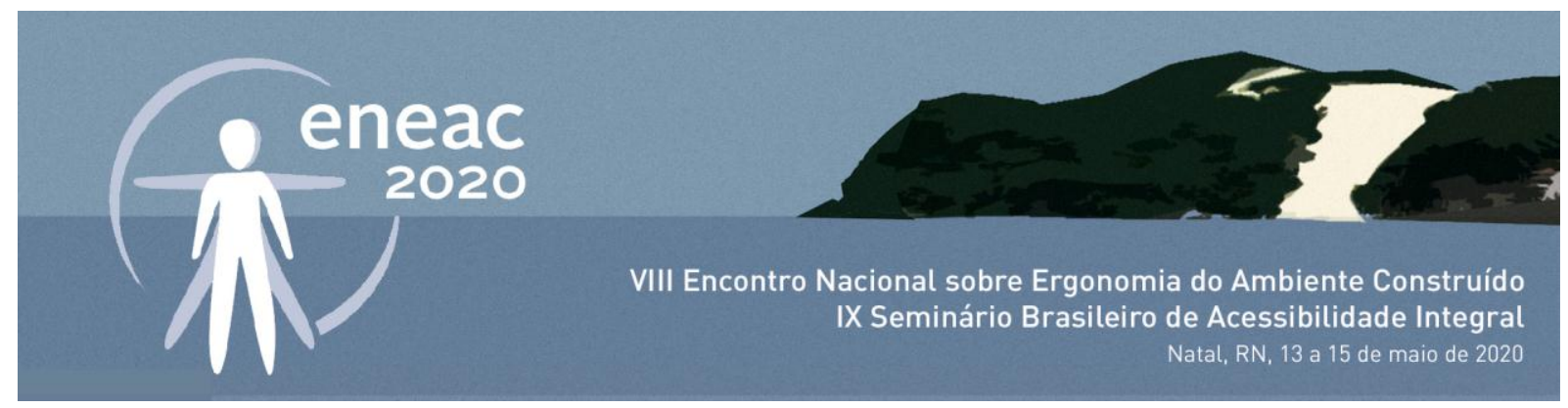

com deficiência ou mobilidade reduzida, observando-se a necessidade de pequenas adequações a serem executadas, nada que exija grandes custos ou reformas significativas. Isso demonstra que a rede hoteleira começa a incorporar em sua gestão as questões relativas à acessibilidade para atender melhor a diversidade de público.

PALAVRAS-CHAVE: Arquitetura; acessibilidade; turismo; hotelaria.

\begin{abstract}
Accessible tourism is a matter of competence for both public authorities, promotion, as an initiative of industry actors - travel agencies, tour operators, transfer and tour transport providers, accommodation managers - in addition to a collective commitment, a business opportunity and a competitive advantage. The aim of this work is to foster the debate on affordable tourism and to verify the level at which the production of the built environment is, specifically, in a hotel chain, comparing a hotel in Brazil and one in another Latin American country, in view of the demands of a diverse world. The work is justified because they are hotels of the same network in coastal cities but in different climate. As a theoretical basis, we sought to read books and articles related to tourism and hospitality (ALEXANDRE, 2013; SOUZA, 2015; VANZELLA et al, 2018; VARGAS \& PAIVA, 2016), in addition to research in official data sources (Ministry of Tourism, 2013; 2018; World Tourism Organization). For the selection of the analysis criteria, the principles of Universal Design (PREISER, 2001; CAMBIAGHI, 2007) were based in order to meet the necessary prerequisites offering orientation conditions - displacement - communication and use (DISCHINGER et al, 2011), without limitations and obstacles. And as parameters the rules and laws of both countries. The field methodology used in fortaleza hotels was based on the Post-Occupation Assessment (ORNSTEIN, 1992; RHEINGANTZ et al., 2009) with emphasis on physical evaluation. Having been prepared a checklist focused on hotel features for on-site surveys with photographic record. The results were positive in relation to the elements that favor accessibility of people with disabilities or reduced mobility, observing the need for minor adjustments to be implemented, nothing that requires significant costs or reforms. This demonstrates that the hotel chain begins to incorporate accessibility issues into its management to better meet public diversity.
\end{abstract}

KEYWORDS: Architecture, accessibility, tourism, hospitality.

\title{
1 INTRODUÇÃO
}

Nas últimas décadas, o setor de serviços vem crescendo no Brasil e no mundo, dentre eles o setor de hospitalidade, fato que gera postos de trabalho e contribui para o desenvolvimento socioeconômico de diferentes países. No Brasil, o Plano Nacional do Turismo de 2018-2022 prevê até 2022 resultados de aumento da chegada de estrangeiros de 6,6 milhões para 12 milhões e a ampliação da receita cambial do turismo dos atuais US\$ 6,6 bilhões para US\$ 19 bilhões (MTur, 2018).

Conforme Vieira (2019),-o turismo no Brasil, em 2018, obteve os seguintes resultados: contribuição do Turismo ao PIB de US\$ 152,5 bilhões (8,1\%); PIB Turístico cresceu 3,1\%, uma das mais elevadas altas na América do Sul, o dobro da economia brasileira; o forte crescimento em gasto internacional é respaldado pelo novo visto eletrônico oferecido a Estados Unidos, Canadá, Austrália e Japão; 6,9 milhões de empregos (7,5\% do total de trabalhos gerados no Brasil); US\$ 6,2 bilhões aportados em 


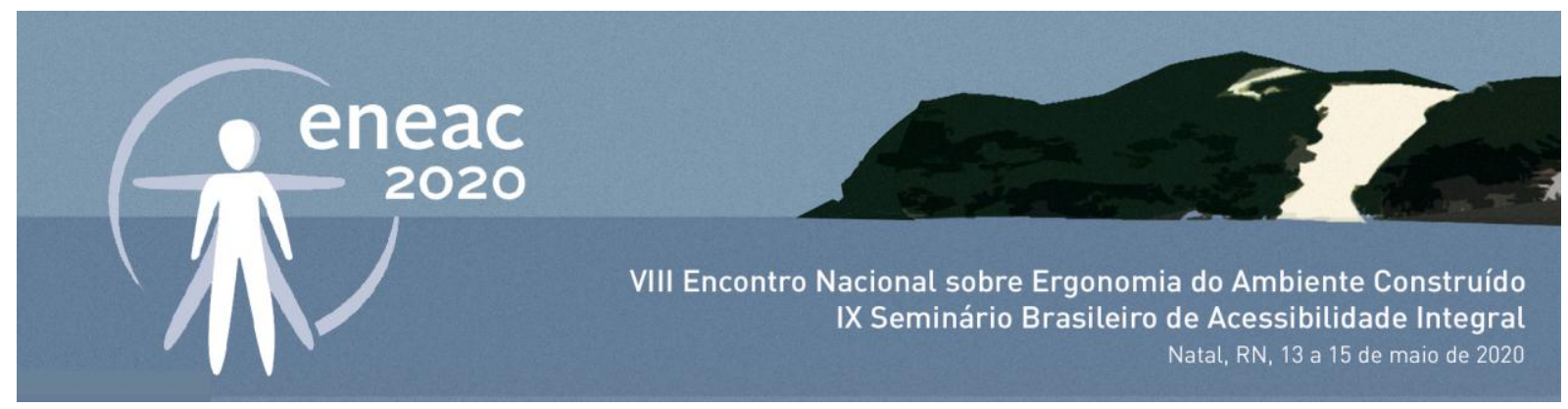

2018 pelos gastos de estrangeiros, $12,8 \%$ de alta contra 2017; lazer $88 \%$ e negócios $12 \%$; principais mercados internacionais 2015-2017: Argentina (36\%), Estados Unidos (8\%), Chile (5\%), Paraguai (5\%) e Uruguai (5\%).

Para atingir melhores níveis de desempenho e obterem resultados satisfatórios, as empresas do setor de hospedagem buscam oferecer serviços que satisfaçam às exigências de seus clientes e usuários, bem como às demandas implementadas pelo governo, como é o caso das normas de acessibilidade para pessoas com deficiência e mobilidade reduzida. Para isso, estas empresas precisam adaptar-se às mudanças que ocorrem em seus ambientes de atuação, inclusive no espaço físico.

O turismo acessível se constitui uma questão de competência tanto das autoridades públicas, na sua promoção e fomento, como uma iniciativa dos agentes do setor - agências de viagens, operadores turísticos, fornecedores de transporte de traslados e passeios, gestores de alojamento - além de um compromisso coletivo, uma oportunidade de negócio e uma vantagem competitiva (SILVA et al, 2019). Neste sentido, a Lei № 10668 DE 02/01/2018, consolida a legislação municipal de Fortaleza e dispõe sobre o Estatuto Municipal da Pessoa com Deficiência. E em seu Capítulo III - Dos Hotéis e Motéis - Art. 18.

Os hotéis e motéis estabelecidos no Município de Fortaleza que tenham mais de 50 (cinquenta) unidades ficam obrigados a adaptar suas instalações, a fim de garantir que pelo menos $2 \%$ (dois por cento) de seus quartos ou apartamentos estejam aptos ao acesso da pessoa com deficiência, inclusive com a utilização de campainha luminosa.

$\S 1$ 을 As adaptações de que trata o caput deste artigo serão definidas em conformidade com ao disposto na Norma Brasileira - NBR - 9050, da Associação Brasileira de Normas Técnicas - ABNT, ou na que vier a substituí-la.

$\S 2$ O Os estabelecimentos localizados em prédios que não consigam atender às exigências previstas neste artigo devem apresentar alternativas para análise junto ao órgão competente.

Nesse processo, Leite e Lucena (2009), assinalam que "os gerentes dessas organizações desempenham papéis importantes, uma vez que possuem o poder de tomar as decisões e de coordenar ações que contribuam para a viabilização das mudanças organizacionais".

No sentido de avaliar estas mudanças e adaptações físicas no setor hoteleiro, o projeto de pesquisa "Acessibilidade arquitetônica $x$ espaços de hospedagem: Fortaleza está preparada para receber pessoas com deficiência e/ou mobilidade reduzida?" - teve início em 2017, por meio do Edital 03/17 PIBIC 2017/2018. A pesquisa se encontra em andamento, tendo para este artigo um foco diferenciado, tivemos a oportunidade de um estudo comparado de hotéis da mesma rede hoteleira em cidades diferentes, é o caso que apresentamos de dois hotéis da mesma rede, sendo um em Fortaleza, Brasil e outro em Lima, no Peru.

O trabalho se justifica por serem hotéis da mesma rede em cidade litorâneas porém de clima diferenciados. Onde se buscou verificar o nível em que se encontra a produção do ambiente construído em face das exigências de um mundo diversificado para que todos os grupos de pessoas possam circular sem restrições ou barreiras que as impeçam de realizar seus percursos (Santiago et al, 2016). Nesse contexto, o edifício do hotel se apresenta como local de uso coletivo, de várias funcionalidades, podendo ser hospedagem ligada ao lazer, ao trabalho, negócios, local de permanência e de circulação, sendo importante para o desenvolvimento socioeconômico da cidade e/ou da região. 


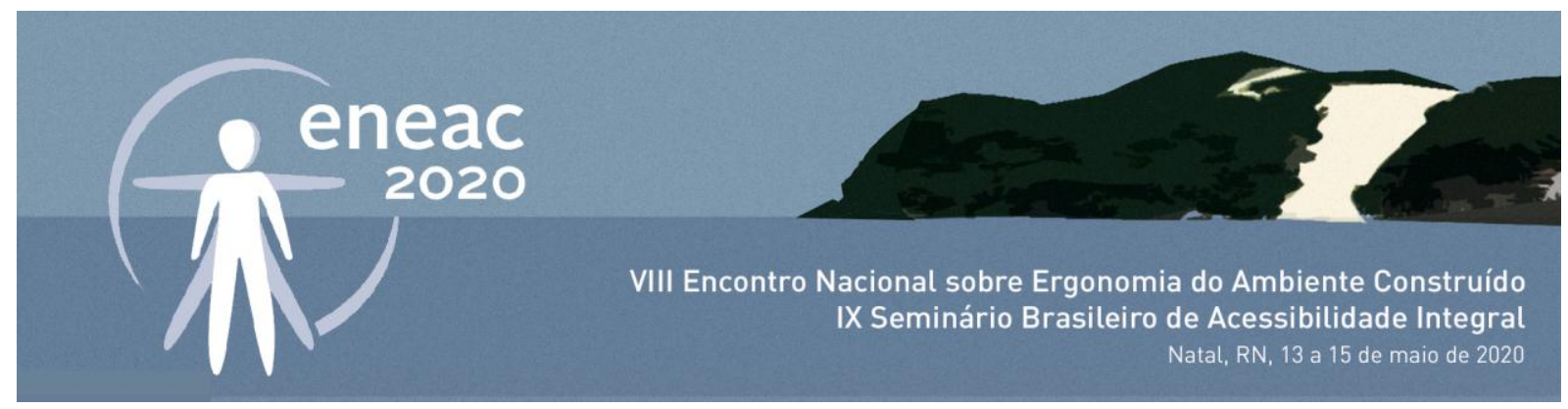

\section{A REDE DE HOTÉIS EM FORTALEZA E LIMA}

O presente estudo pretende trazer uma contribuição ao debate sobre acessibilidade espacial no ambiente construído, tendo como foco de pesquisa o setor hoteleiro. Especificamente para este artigo, hotéis de uma mesma rede hoteleira.

Segundo o site da referida rede de hotéis, existem 2.434 hotéis da rede no mundo distribuídos na Europa, Ásia, Austrália-Pacífico, Oriente Médio, América do Norte e América do Sul. Nosso recorte inicial é a América do Sul, onde existem 262 hotéis espalhados nos países - Brasil, Chile, Peru, Argentina, Colômbia, Paraguai e Uruguai. Com a pretensão de analisar e comparar dois hotéis de países diferentes, sendo um do Brasil e um de outro país, foi escolhido um hotel na cidade de Fortaleza/CE, onde está em andamento pesquisa sobre acessibilidade em hotéis e o outro em Lima, Peru, pela oportunidade de ter sido visitado e analisado.

Em Fortaleza, esta rede apresenta dois hotéis: o hotel $A$, situado na Praia de Iracema, hotel três estrelas, (Figura 1) que fica mais próximo da Beira Mar; e o Hotel B, classificado como três estrelas, (Figura 2), com características de hotel executivo, localizado nas proximidades do Centro de Eventos do Ceará, no bairro Guararapes.

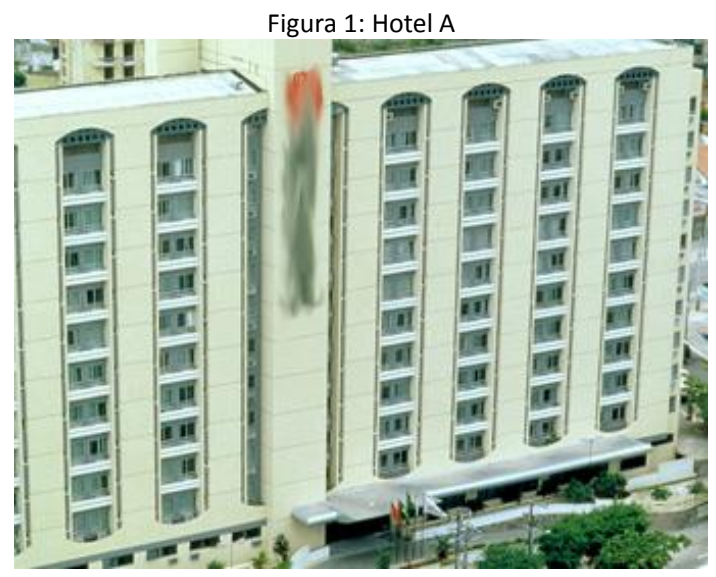

Fonte: Google. Site do hotel

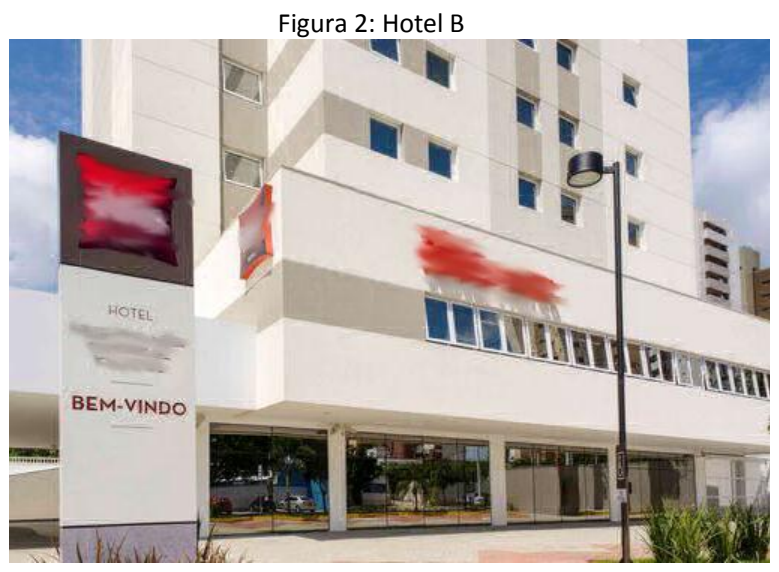

Fonte: Google. Site do hotel

\section{Hotel B}

Selecionamos para o estudo comparado, o Hotel B devido as características de público e de certa forma a proximidade com a área nobre da cidade. Situado nas proximidades do Centro de Eventos e da Avenida Washington Soares, avenida de fluxo intenso limite entre os bairros Guararapes e o Bairro Edson Queiroz (Mapa 2). 

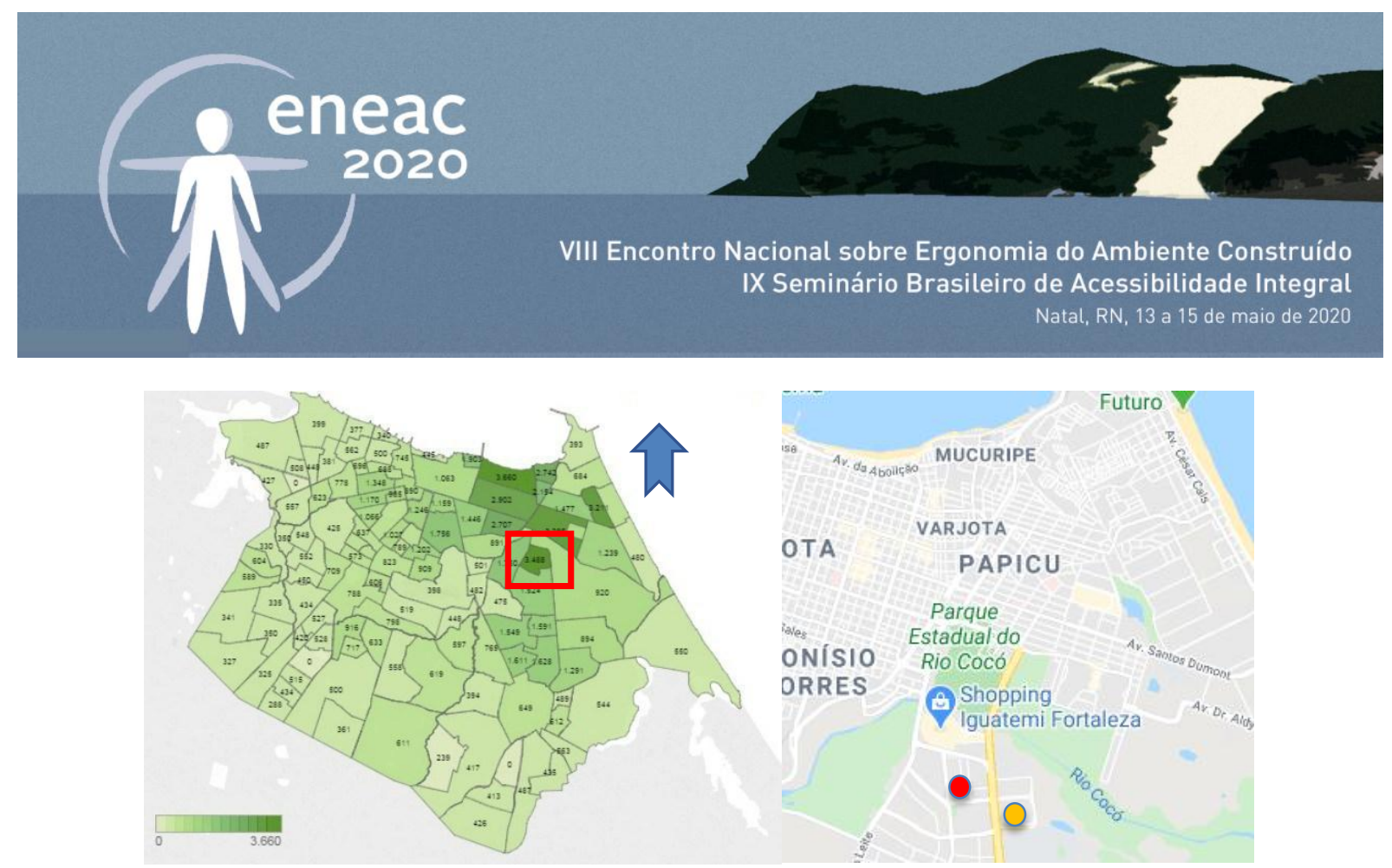

Fonte: Google. Site do hotel, 2019.

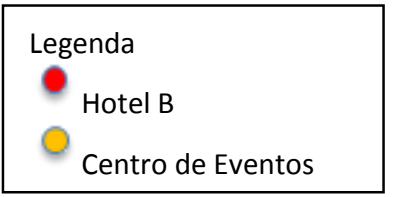

Na cidade de Lima no Peru, esta rede hoteleira apresenta três hotéis no distrito de Miraflores- o Hotel C - situado na Lizardo Alzamora Este, San Isidro (Figura 3), hotel quatro estrelas; o Hotel D - situado na avenida Reducto (Figura 4), hotel três estrelas; o Hotel E - na avenida Jose Larco (Figura 5), hotel três estrelas.

Figura 3: Hotel C

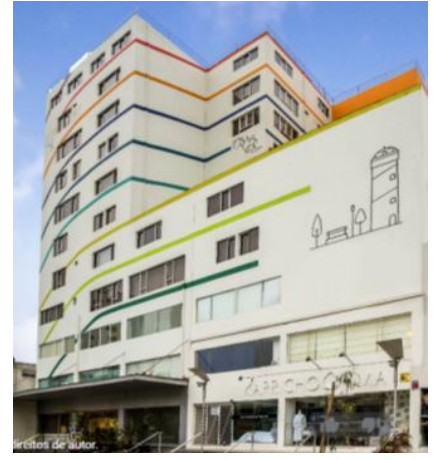

Fonte: Google. Site do hotel
Figura 4: Hotel D

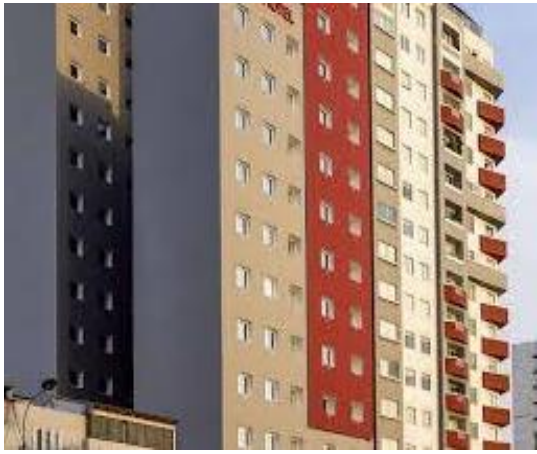

Fonte: Google. Site do hotel
Figura 5: Hotel E

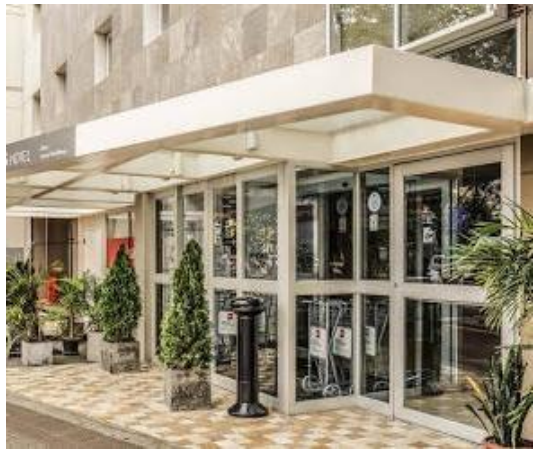

Fonte: Google. Site do hotel

\section{Hotel E}

Os três hotéis apresentam em seu site a condição de acessibilidade para pessoas em cadeira de rodas e para crianças, contudo, o Hotel E foi o selecionado para o estudo comparado, pelo fato de além do critério acima citado, ter sido visitado por membro da pesquisa e sua pela localização próxima do litoral, o que representa assemelhar-se com a localização do Hotel da mesma rede em Fortaleza. Situase em avenida de grande movimento que desemboca no Parque Alfredo Salazar (Mapa 3). 

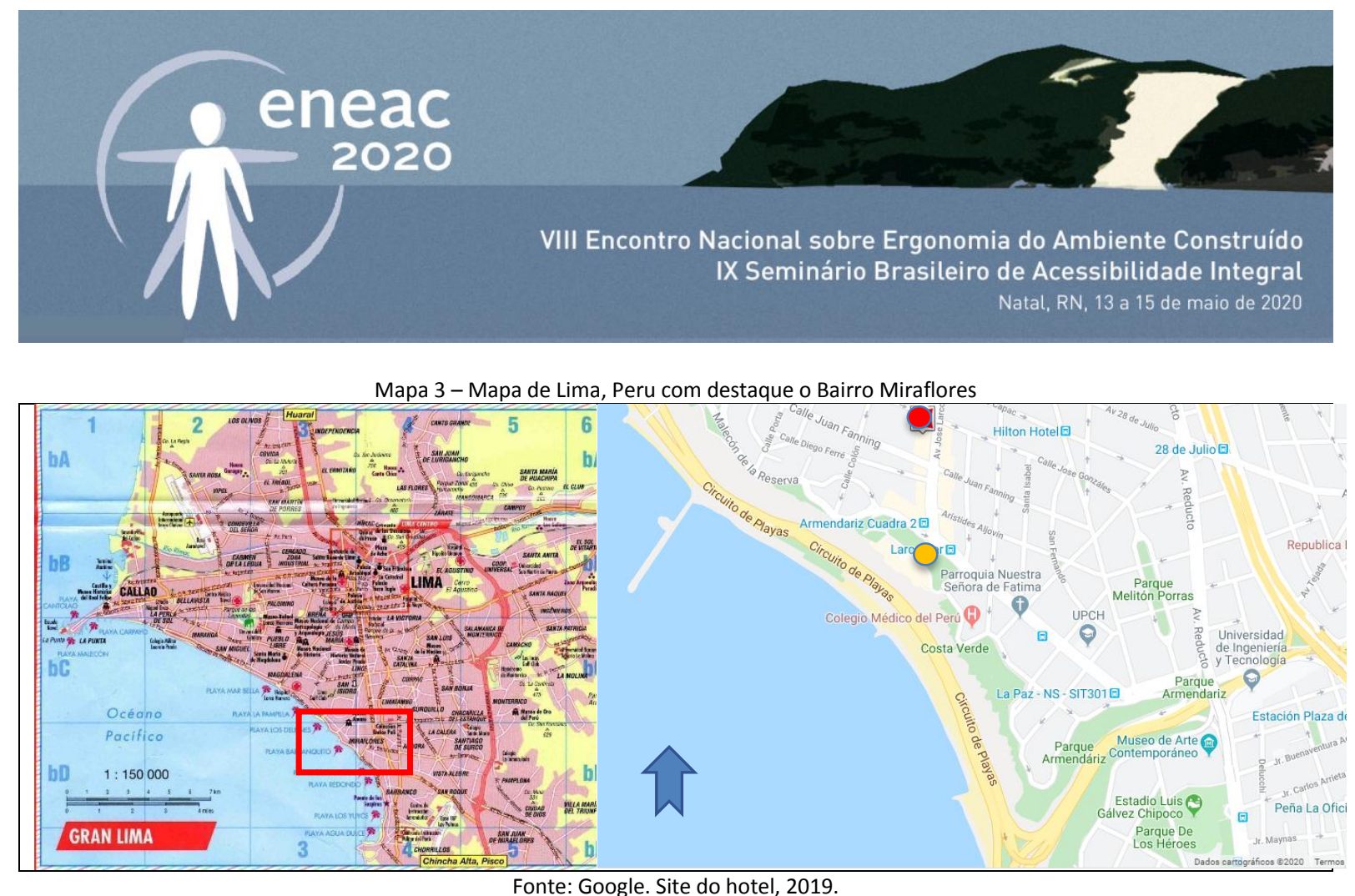

Fonte: Google. Site do hotel, 2019.

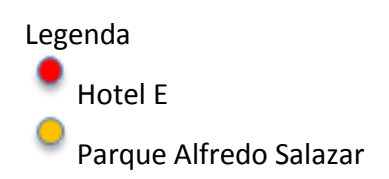

\section{METODOLOGIA}

Como fundamentação teórica, buscou-se leitura de livros e artigos relacionados ao turismo e à temática de hotelaria (ALEXANDRE, 2013; SOUZA, 2015; VANZELLA et al, 2018; VARGAS \& PAIVA, 2016), redes de hotéis, bem como a pesquisa em fontes de dados oficiais, como o Ministério do Turismo e a Organização Mundial do Turismo (OMT), sobre o turismo no Brasil e no mundo.

Neste artigo, apresentamos os critérios de análise, utilizando-se como base princípios do Desenho Universal (PREISER, 2001; CAMBIAGHI, 2007) e como parâmetros as normas e leis sobre o assunto (Decreto 5.296/2004; NBR 9050/2015; LBI N. 13.146/2015; Lei no 27.050/1998 - Lei Geral da Pessoa com Incapacidade - Lima, Peru). Apresentamos também alguns resultados, cujo objetivo principal é verificar o quanto hotéis de uma mesma rede em cidades diferentes, enquanto espaços de hospedagem, atendem a pré-requisitos necessários para que esses espaços funcionem como agregadores de pessoas, oferecendo condições de orientação - deslocamento - comunicação e uso (Dischinger, Bins Ely e Piardi, 2011), sem limitações e obstáculos.

A metodologia de campo utilizada nos hotéis de Fortaleza, teve como base a Avaliação Pós-Ocupação de Ornstein (1992) e Rheingantz et al. (2009). Tendo sido elaborado um checklist focado em funcionalidades de hotel para os levantamentos in loco. Além disso, em alguns pontos e equipamentos dos hotéis avaliados foram utilizados registro fotográfico e levantamento métrico como forma de conferir a adequação.

Cada levantamento foi realizado de forma diferenciada, em Fortaleza seguiu-se o padrão já utilizado na pesquisa em que os pesquisadores simulam a utilização dos espaços com rotas de um hóspede no hotel. A rota padrão se inicia na área externa do hotel, avaliando os passeios e o estacionamento aberto ao público e, posteriormente, a entrada principal de acesso à edificação, de forma a verificar os seguintes parâmetros: 1 - Passeios (largura e pavimentação do passeio; existência de rebaixamento de guias; obstáculos; piso tátil ou guia de balizamento para pessoas com deficiência 


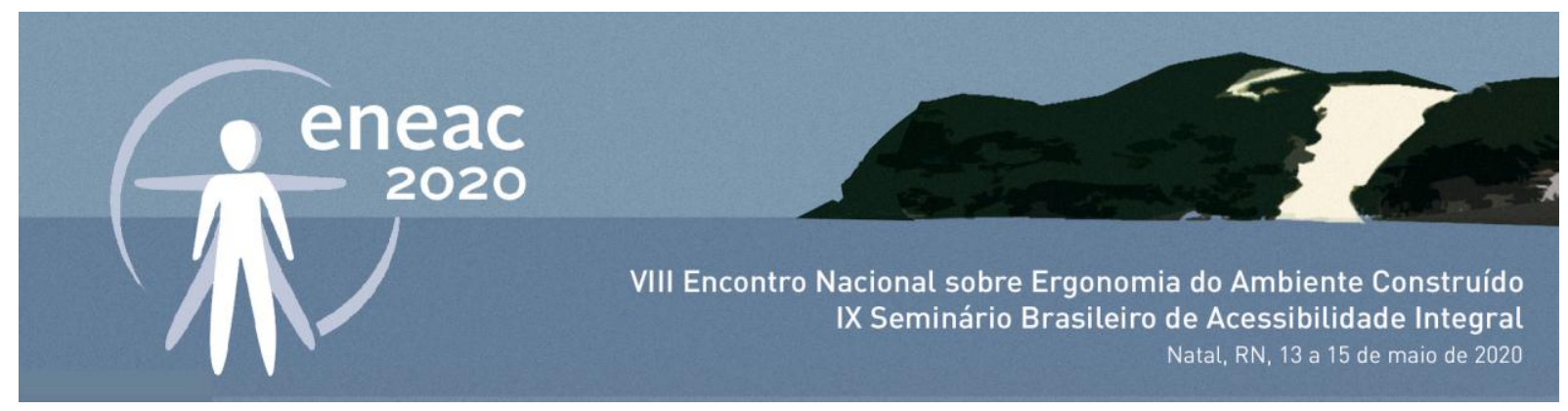

visual; e paisagismo); 2 - Estacionamento aberto ao público: existência de vagas exclusivas para idosos e para pessoas com deficiência; 3 - Acesso à edificação: presença de escada e/ou rampas (confirmado a existência, observação da pavimentação, guarda-corpo e corrimãos); portas de acesso ao hotel e presença de algum obstáculo. No interior do hotel, o levantamento segue pela rota de cadastramento no balcão de recepção, seguindo para a sala de estar/espera, banheiros e restaurante. Por último, avaliação da Suíte acessível - condições de largura da porta de acesso; espaço para circulação de cadeira de rodas; altura do mobiliário e banheiro acessível. Além disso, a verificação da existência e condições de estacionamento privativo com existência de vagas exclusivas para idosos e para pessoas com deficiência.

Ainda relativo a análise geral é verificado tipo de pavimentação de acesso e entrada do hotel, se está nivelado e com inclinação transversal adequada. Se existe uma rota acessível, de forma que o hóspede possa entrar, passar pela recepção e áreas comuns e de lazer, seguindo até a suíte, de forma autônoma e segura. Verificar a existência de sinalização visual e tátil em conformidade com a NBR 9050. Quanto à dimensões de portas, guarda-corpos, mobiliário, elevadores, sanitários, devem estar adequadas ao uso por pessoas com deficiência, pessoas com mobilidade reduzida e crianças.

No hotel em Lima, a pesquisa foi um pouco mais restrita, quanto a verificação de estacionamentos, por outro lado, foram observados outros elementos como a informação nos elevadores da distribuição das suítes acessíveis por andar.

Para efeito de comparação, buscamos a legislação peruana e a verificação in loco comparando com as condições de acessibilidade nas recomendações da Associação Brasileira de Normas Técnicas. Sobre acessibilidade na legislação peruana, contamos com a publicação Acessibilidade - Comparação das Leis dos Países do Mercosul (2008) de autoria de Antônia M. de Fátima Oliveira, Consultora Legislativa da Área XIII Desenvolvimento Urbano, Trânsito e Transportes, publicada pela Câmara dos Deputados, onde consta a Lei no 27050, de 18 de dezembro de 1998 - Lei Geral da Pessoa com Incapacidade Lima, Peru.

\section{RESULTADOS E DISCUSSÃO}

Muitos hotéis em Lima possuem suítes acessíveis. Segundo o site https://www.hoteis.com, sobre 280 hotéis com acessibilidade no quarto, as melhores opções de hotel com acessibilidade no quarto mais recomendados por usuários são: 1 . Hampton by Hilton Lima San Isidro; 2. Apartamentos Lima 501; 3. ALU Apartments - Miraflores Boardwalk; 4. Areas Temporales - Near Larcomar Shopping Center; 5. Lux Miraflores Apartments Ocean View. Segundo o site citado, um hotel adaptado para pessoas com deficiência e mobilidade reduzida, possui rampas de acesso, elevador para cadeirantes, barras de locomoção na piscina, telefones que convertem a voz em texto, informativos em Braile e computadores adaptados. Os banheiros e quartos possuem espaço para usuários de cadeira de rodas e acessos facilitados. Embora o Hotel E não esteja entre os mais citados, foi selecionado por ser da da mesma rede do hotel analisado em Fortaleza, ter localização em cidade litorânea e ter sido visitado por pesquisador de Fortaleza.

Para melhor apresentar os resultados desta pesquisa, foram elaborados quadros comparativos (Quadros 2, 3 e 4) das situações em que a acessibilidade se torna um diferencial para o setor 


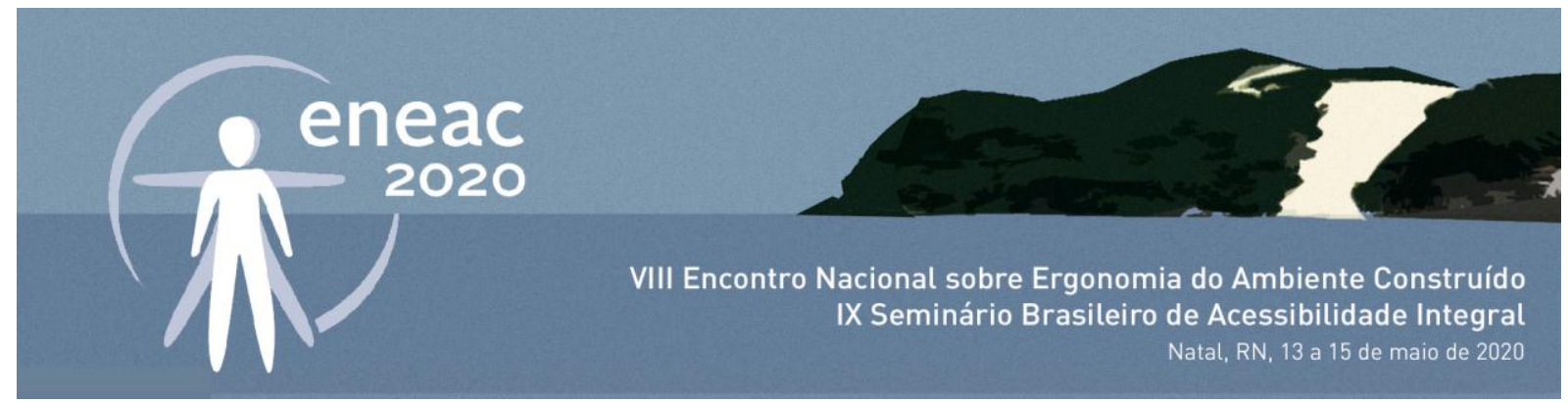

hoteleiro na acomodação de hóspedes de forma universal. E para a avaliação foi criada uma legenda de nível de atendimento às normas e legislação (Quadro 1).

Quadro 1: Legenda da Avaliação

\begin{tabular}{|l|l|l|}
\hline & Atende a NBR 9050/2015 & Atende a Lei no 27050/1998 - Peru \\
\hline & Atende parcialmente NBR 9050/2015 & Atende parcialmente Lei no 27050/1998 - Peru \\
\hline Não atende a NBR 9050/2015 & Não atende a Lei no 27050/1998 - Peru \\
\hline & Atendimento desatualizado (NBR 9050/2004) & \\
\hline
\end{tabular}

Para esclarecimento do Quadro 2, não foi elencado a Legislação peruana, por ser menos detalhada que a norma brasileira, assim, optou-se por fazer referência à NBR 9050/2015.

Quadro 2: Comparativo HOTEIS - em Fortaleza e em Lima (Passeio e acesso a edificação)

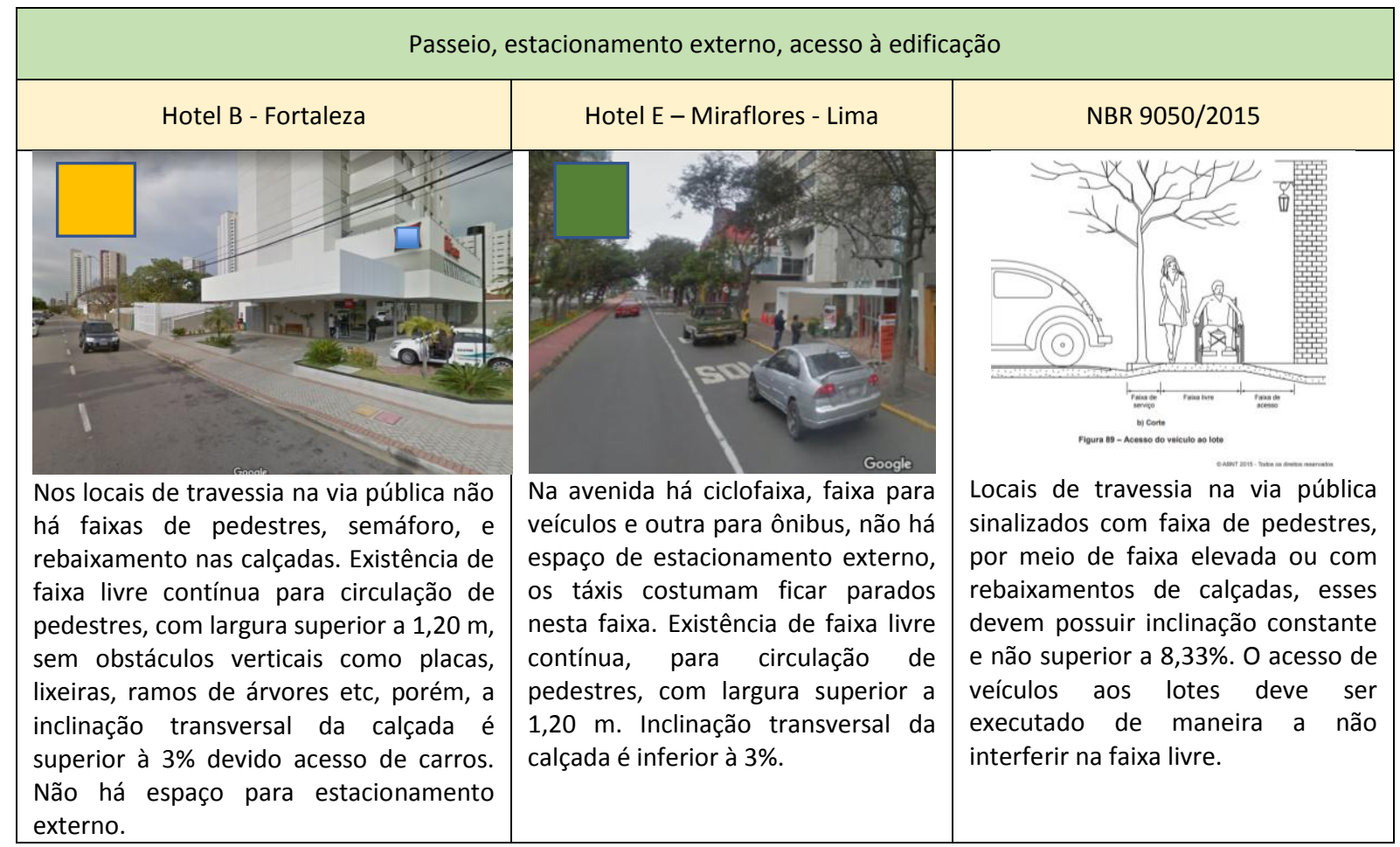




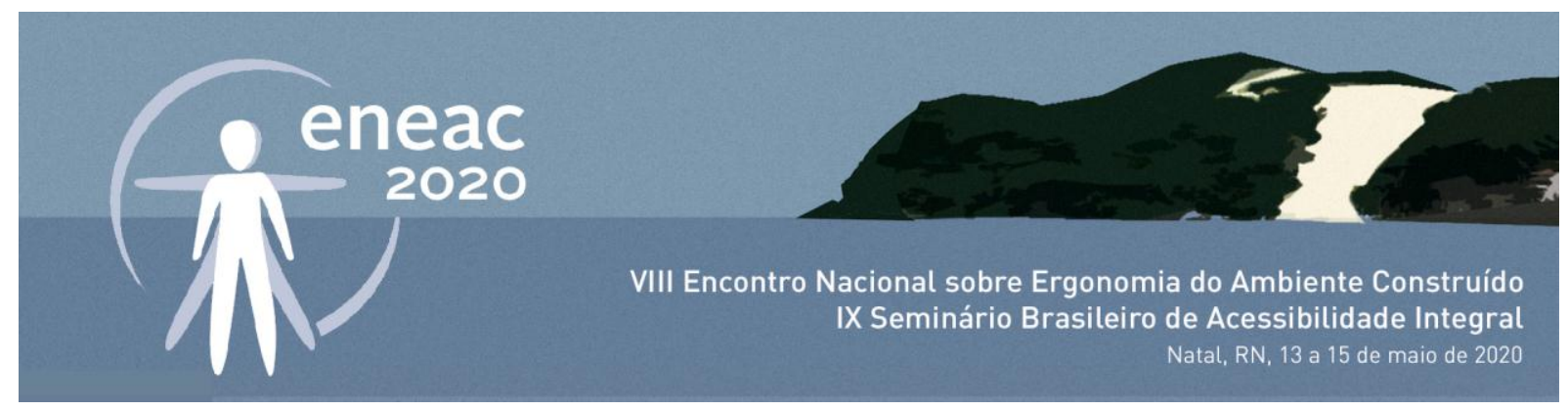

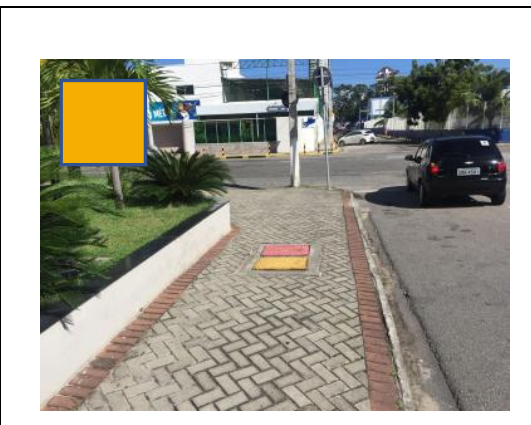

Os pisos dos passeios têm superfícies regulares, não trepidantes para dispositivos com rodas. Existência de elemento, natural ou edificado, que possa ser utilizado como linha-guia (muros, grades, etc.). Inclinação transversal acentuada dificulta passagem de pessoas com deficiência.

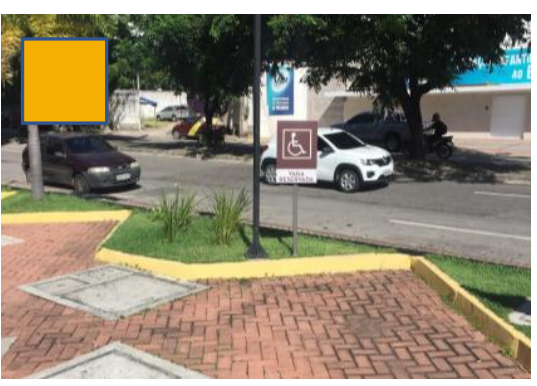

Estacionamento dentro do lote com vagas reservadas e sinalizadas para pessoas idosas e com deficiência. Entrada para estacionamento não é separada da entrada para pedestres. Não há espaço adicional de circulação de $1,20 \mathrm{~m}$.

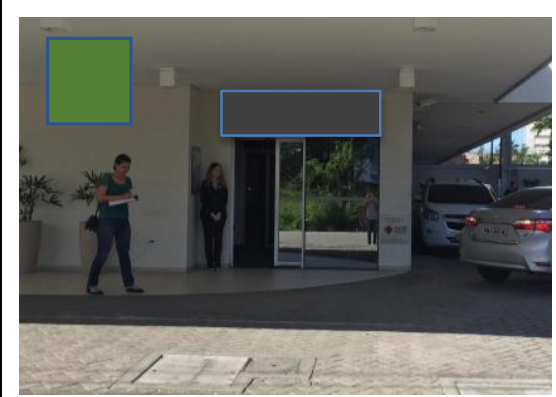

No acesso à edificação não há grandes desniveis que interfiram na faixa livre de

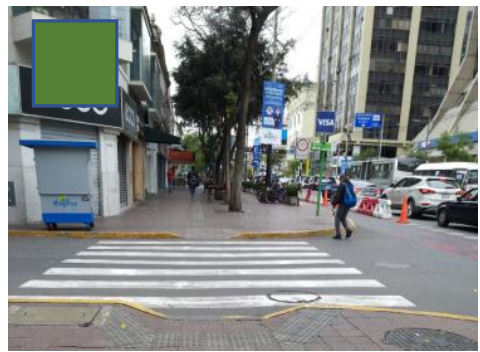

Existência de faixa de pedestre junto do rebaixamento nas calçadas. Existência de piso direcional e de alerta na faixa livre, que possui inclinação transversal inferior à 3\%, com superfície regular, não trepidante e antiderrapante.

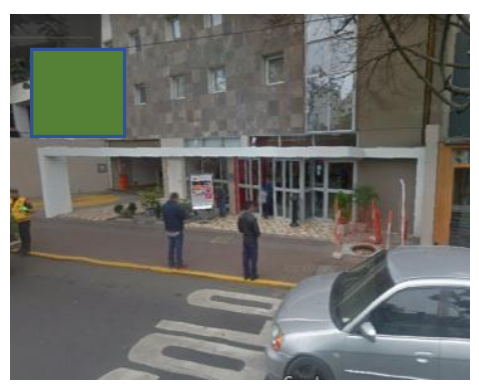

Não há espaço para estacionamento dentro do lote, a configuração espacial não enquadra estacionamento na frente da edificação.

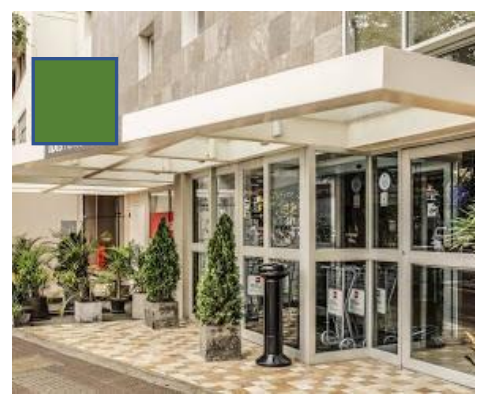

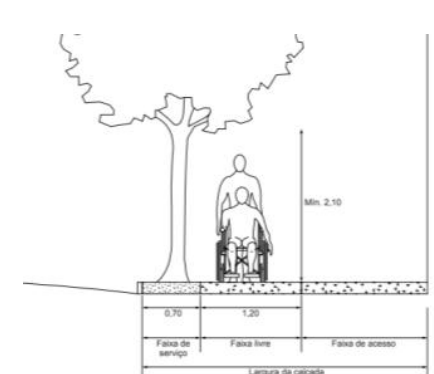

Deve existir faixa livre contínua, para circulação de pedestres, com largura mínima de $1,20 \mathrm{~m}$ e altura livre mínima de 2,10 m, (sem obstáculos verticais como: placas, lixeiras, beirais, ramos de árvores etc.). Deve possuir inclinação transversal de, no máximo, 3\%, com superfície regular e antiderrapante. Existência de linhaguia identificável ou piso tátil direcional e de alerta. Suporte informativo tátil no passeio que permita a identificação do edifício.

No caso de existirem vagas de estacionamento na via pública, deve haver vagas reservadas para pessoas idosas e com deficiência próximas à entrada do edifício. Se houver estacionamento dentro do lote, sua entrada deve ser facilmente percebida, e separada da entrada dos pedestres. Pelo menos $2 \%$ das vagas devem ser reservadas para pessoas com deficiência, estando vinculadas a uma rota acessível que interligue os setores do hotel. Essas vagas devem possuir espaço adicional de circulação com largura mínima de 1,20 m.

Todas as entradas da edificação devem ser acessíveis, considerandose os trajetos dos passeios e as portas de entrada. Na existência de desnível entre a circulação externa e a porta de entrada, deve haver rampa ou equipamento eletromecânico que permita pleno acesso. $O$ piso do trajeto deve ter superfície regular, não trepidante para dispositivos com rodas, e antiderrapante. Desníveis entre 5 e 


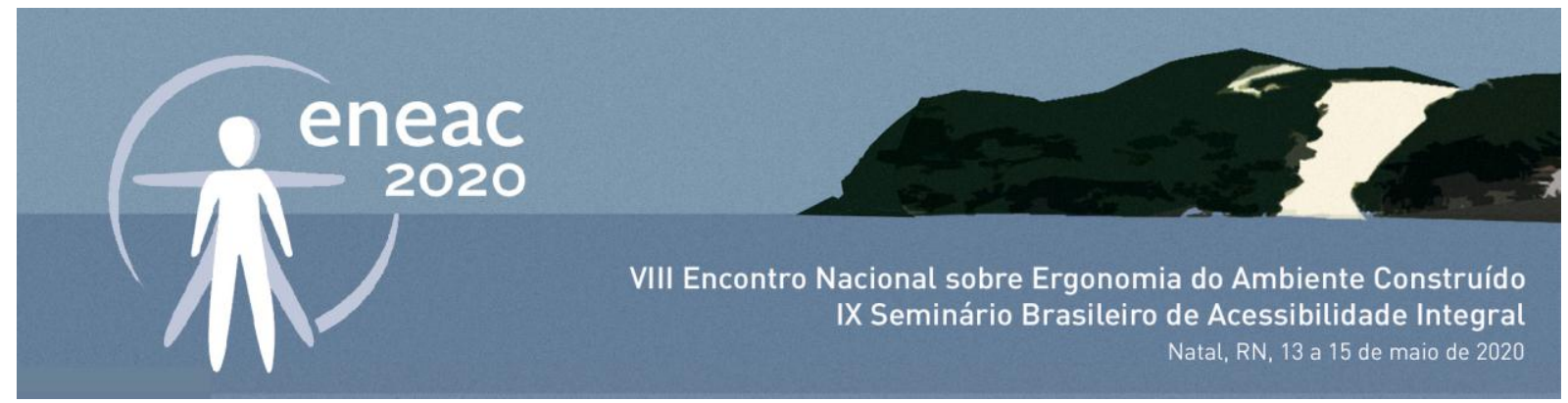

$1,20 \mathrm{~m}$, porém com sinalização tátil e visual ineficaz. Há nivelamento do piso da circulação externa e porta de acesso.
Acesso sem desnível e porta de abertura automática, facilitando entrada de pessoa com deficiência.
$20 \mathrm{~mm}$ devem ser chanfrados, com inclinação máxima de $50 \%$.

Quadro 3: Comparativo HOTEIS - em Fortaleza e em Lima (Recepção e estar)

\begin{tabular}{|c|c|c|}
\hline \multicolumn{3}{|c|}{ Recepção, estar. } \\
\hline Hotel B - Fortaleza & Hotel E - Miraflores - Lima & NBR 9050/2015 \\
\hline $\begin{array}{l}\text { Inexistência de Mapa Tátil e piso tátil } \\
\text { direcional, ou qualquer sinalização } \\
\text { visual voltada para pessoas com } \\
\text { deficiência. Contraste entre cores dos } \\
\text { móveis, piso e parede. Balcão de } \\
\text { recepção de fácil apreensão, com } \\
\text { espaço reservado para cadeirantes, } \\
\text { com aberturas inferiores livres. }\end{array}$ & $\begin{array}{l}\text { Inexistência de Mapa Tátil e piso tátil } \\
\text { direcional. Contraste entre cores dos } \\
\text { móveis, piso e parede. } \\
\text { Balcão de recepção bem localizado e } \\
\text { de fácil apreensão com aberturas } \\
\text { inferiores livres. }\end{array}$ & $\begin{array}{l}\text { Na recepção deve haver suporte } \\
\text { informativo tátil que permita a } \\
\text { identificação do local, contraste de cor } \\
\text { entre piso, parede e móveis, para } \\
\text { facilitar a orientação de pessoas com } \\
\text { baixa visão. O balcão de informações } \\
\text { deve estar localizado em rota acessível, } \\
\text { com altura entre } 0,90 \mathrm{~m} \text { e } 1,05 \mathrm{~m} \text { em } \\
\text { relação ao piso, com largura livre } \\
\text { mínima sob a superfície de } 80 \mathrm{~cm} \text {. } \\
\text { Ainda, o balcão precisa possuir altura } \\
\text { livre de } 73 \mathrm{~cm} \text { sob o balcão e } \\
\text { profundidade livre inferior de } 30 \mathrm{~cm} \text {. }\end{array}$ \\
\hline & & +1 \\
\hline $\begin{array}{l}\text { Layout flexível, possibilitando livre } \\
\text { circulação e espaços que acomodam } \\
\text { cadeiras de rodas. Presença de largos sofás } \\
\text { que podem ser utilizados por obesos. } \\
\text { Inexistência de sinalização tátil ou visual } \\
\text { adequada para pessoas com deficiência. }\end{array}$ & $\begin{array}{l}\text { Layout semelhante ao de Fortaleza: } \\
\text { flexibilidade de uso com possibilidade de } \\
\text { livre circulação e espaços que acomodam } \\
\text { cadeiras de rodas. Presença de largos sofás } \\
\text { que podem ser utilizados por obesos. } \\
\text { Inexistência de sinalização tátil ou visual. }\end{array}$ & $\begin{array}{l}\text { Mobiliário localizado fora da faixa livre de } \\
\text { circulação, com espaço reservado para } \\
\text { pessoas em cadeira de rodas junto ao } \\
\text { mobiliário de espera. Deve existir pelo } \\
\text { menos um assento destinado às pessoas } \\
\text { obesas. }\end{array}$ \\
\hline 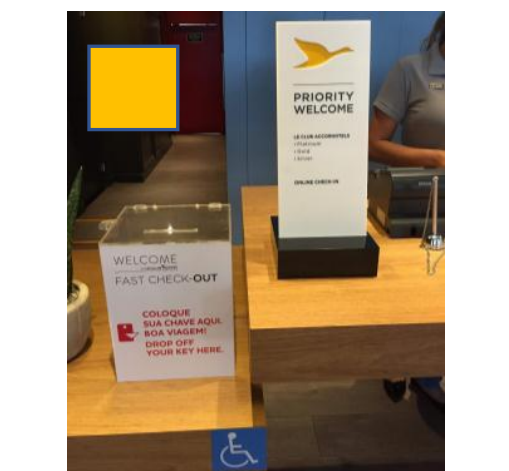 & $\leftarrow$ & 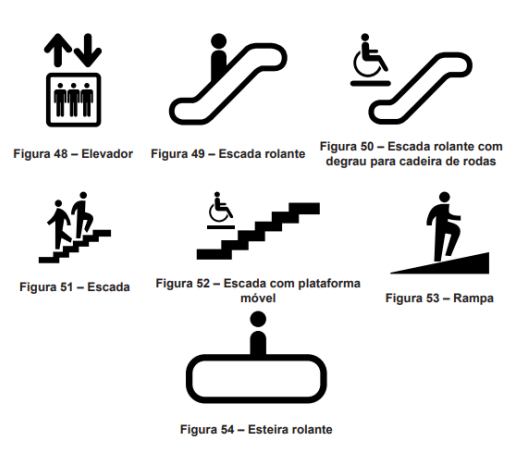 \\
\hline
\end{tabular}




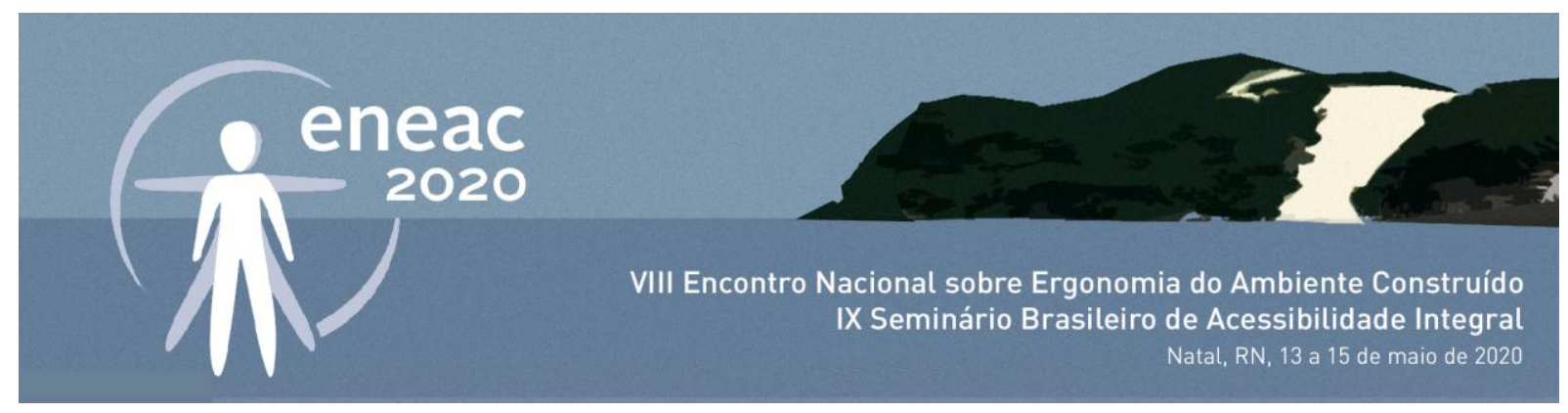

\begin{tabular}{|l|lrl|l|}
\hline $\begin{array}{l}\text { Existência de suporte informativo tátil } \\
\text { que permite a identificação do local ou } \\
\text { atendimento especializado para } \\
\text { pessoas com deficiência. Não } \\
\text { sinalização visual que configure rota } \\
\text { acessível. }\end{array}$ & $\begin{array}{l}\text { Sinalização visual espaçada e de } \\
\text { indicação da suíte acessível, } \\
\text { configurando rota acessível. }\end{array}$ & $\begin{array}{l}\text { A sinalização existente na edificação } \\
\text { deve permitir ao usuário localizar-se e } \\
\text { definir rotas para o uso do edifício de } \\
\text { forma autônoma. Existindo Mapa Tátil, } \\
\text { o piso tátil direcional guia as pessoas } \\
\text { com deficiência visual até a sua } \\
\text { localização. }\end{array}$ \\
\hline
\end{tabular}

Quadro 4: Comparativo HOTEIS - em Fortaleza e em Lima (Suíte Acessível)

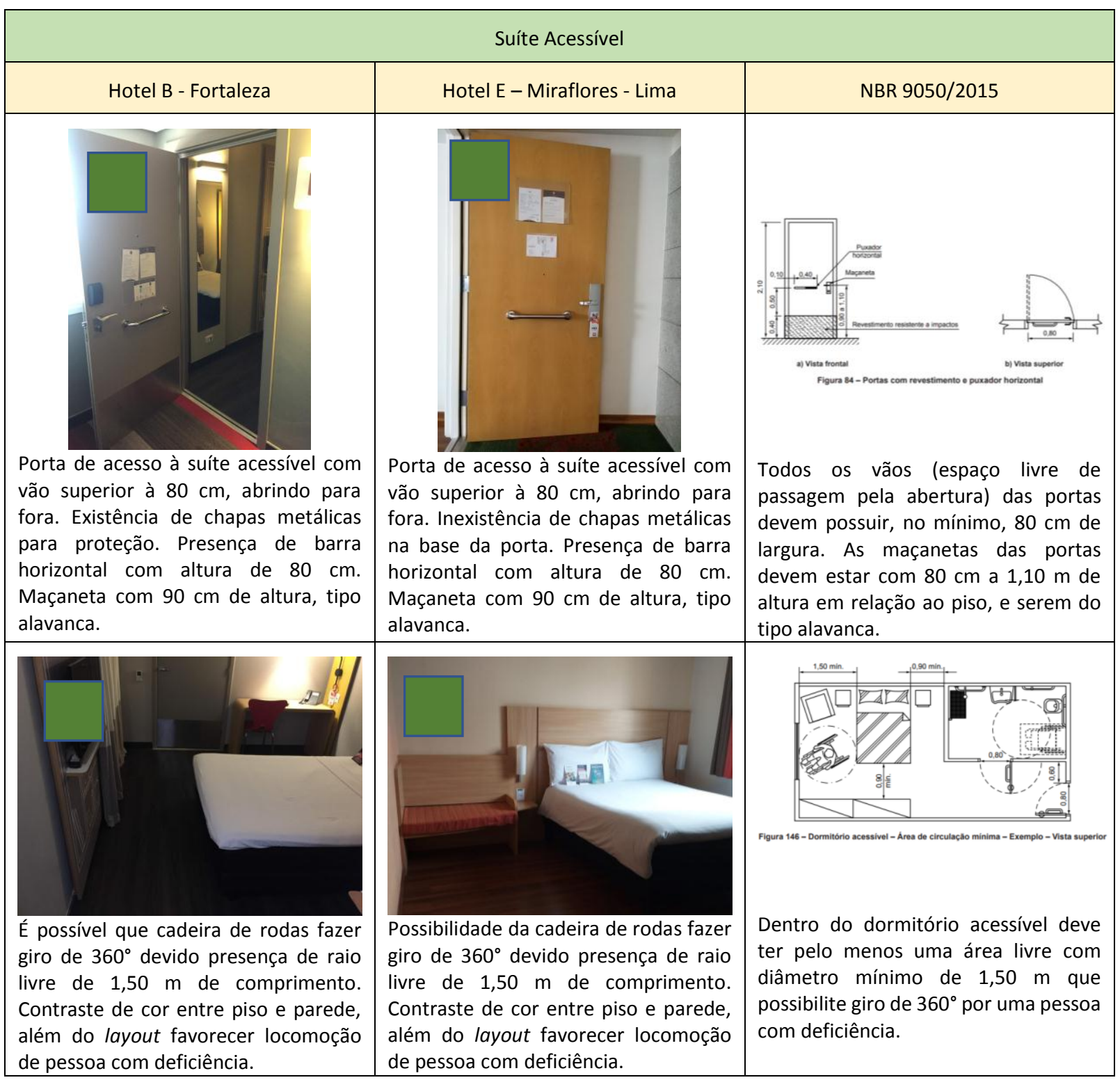



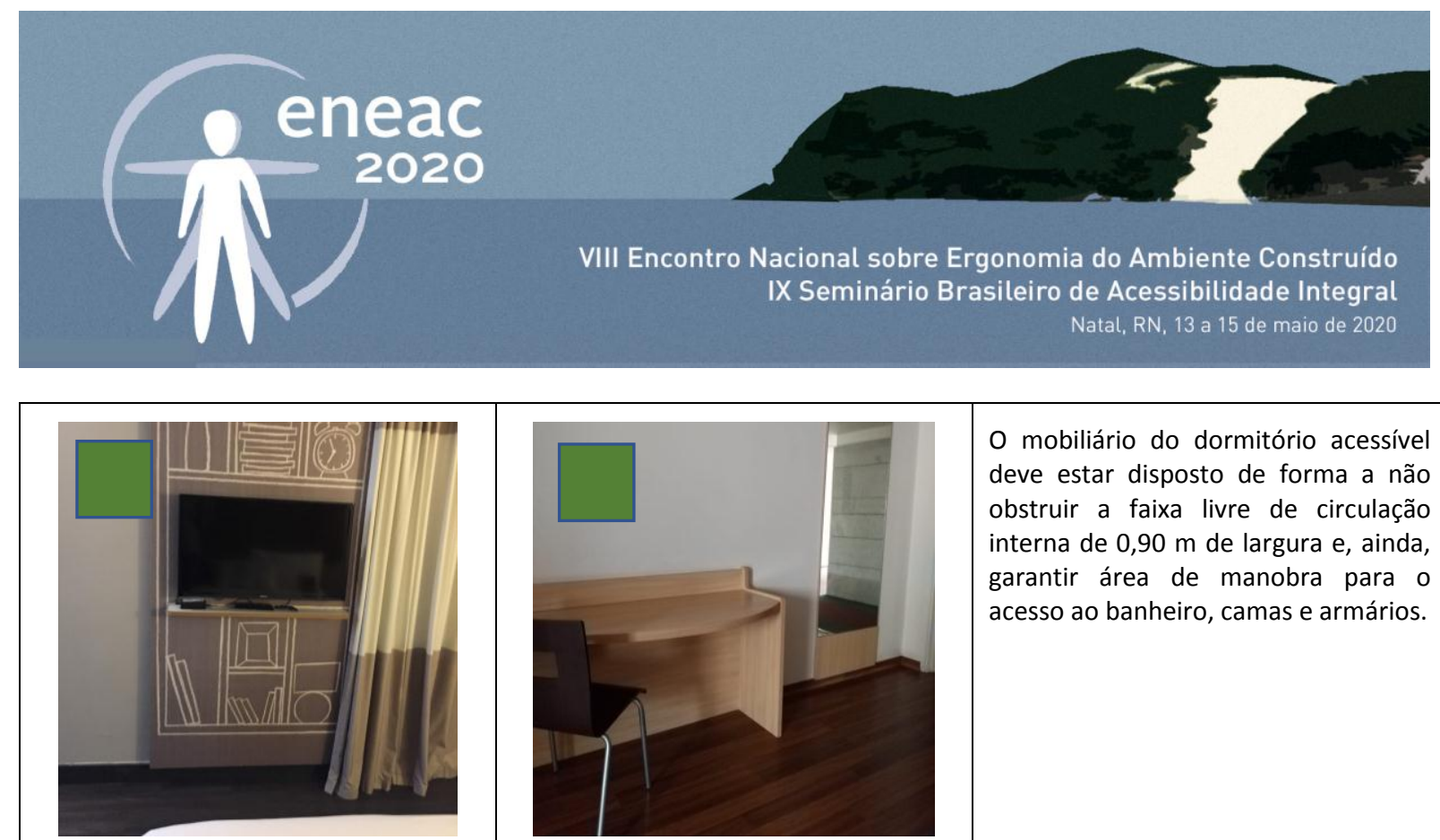

TV posicionada em móvel que não estrangula circulação, tornando livre o uso da cadeira de rodas.

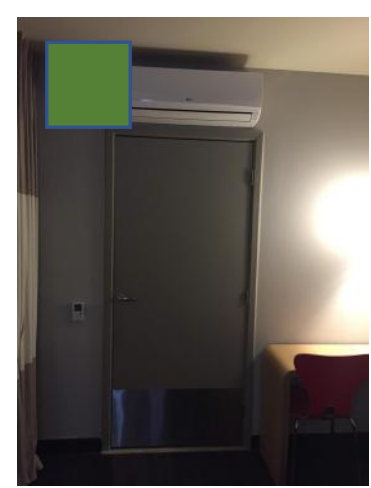

Porta de acesso ao banheiro com $80 \mathrm{~cm}$ de vão, abrindo para fora. Existência de chapas metálicas para proteção. Maçaneta das portas com $90 \mathrm{~cm}$ de altura, do tipo alavanca.

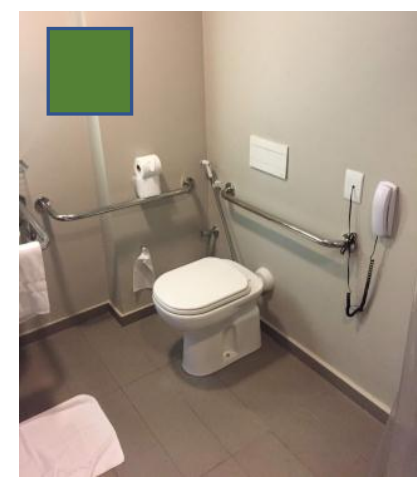

Contraste de cor de piso e parede, facilitando locomoção de pessoas com deficiência visual. Barras de apoio com altura de $0,75 \mathrm{~m}$ e $0,75 \mathrm{~m}$ de comprimento. Descarga acionada por pressão.

Possibilidade da cadeira de rodas fazer giro de $360^{\circ}$ devido presença de raio

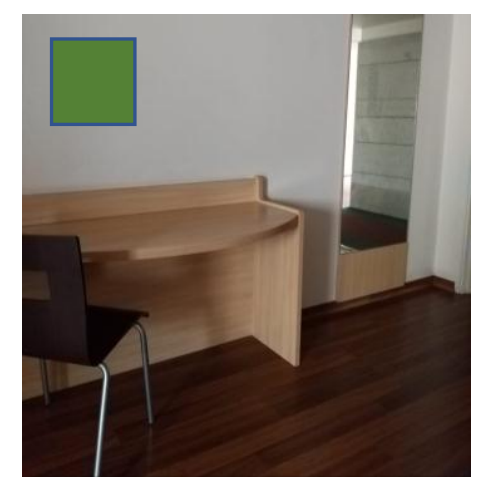

Mobiliário disposto não atrapalha circulação interna da suíte. Abertura inferior existente em mesa, o que facilita acesso de cadeirante.

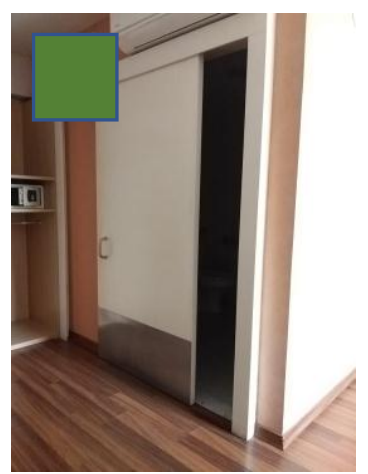

Porta de correr com trilhos na parte inferior, nivelados com 0 piso. Abertura superior à $80 \mathrm{~cm}$, existência de chapa metálica para proteção.

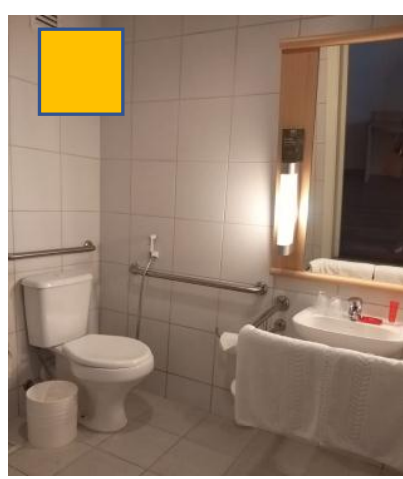

Inexistência de contraste de cor de piso e parede, prejudicando locomoção de pessoas com baixa visão. Devido caixa acoplada, barra de apoio acima do sanitário possui altura superior à 0,75 $\mathrm{m}$. Possibilidade da cadeira de rodas fazer giro de $360^{\circ}$ devido presença de raio livre de $1,50 \mathrm{~m}$ de comprimento.
O mobiliário do dormitório acessível deve estar disposto de forma a não obstruir a faixa livre de circulação interna de 0,90 m de largura e, ainda, garantir área de manobra para o acesso ao banheiro, camas e armários.

A porta do sanitário acessível (ou boxe acessível), quando for do tipo de eixo vertical, deve abrir totalmente para fora, tendo vão (espaço livre de passagem pela abertura) de, no mínimo, $80 \mathrm{~cm}$ de largura. As maçanetas das portas devem estar com $80 \mathrm{~cm}$ a $1,10 \mathrm{~m}$ de altura em relação ao piso, e serem do tipo alavanca. No caso de porta de correr, os trilhos devem ser instalados na sua parte superior. No caso de porta de correr com trilhos na parte inferior, estes devem estar nivelados com o piso, de modo que eventuais frestas tenham largura máxima de $15 \mathrm{~mm}$.
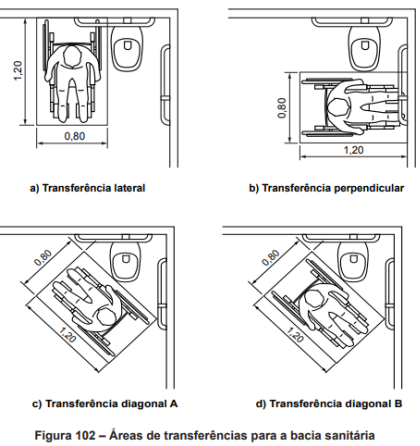

No sanitário deve haver contraste entre piso, parede e equipamentos, a fim de facilitar a orientação de pessoas com baixa visão e, ainda, o piso deve ser antiderrapante. É preciso garantir a circunscrição de um círculo com 1,50 m de diâmetro no piso, além da área necessária para a transferência lateral, 


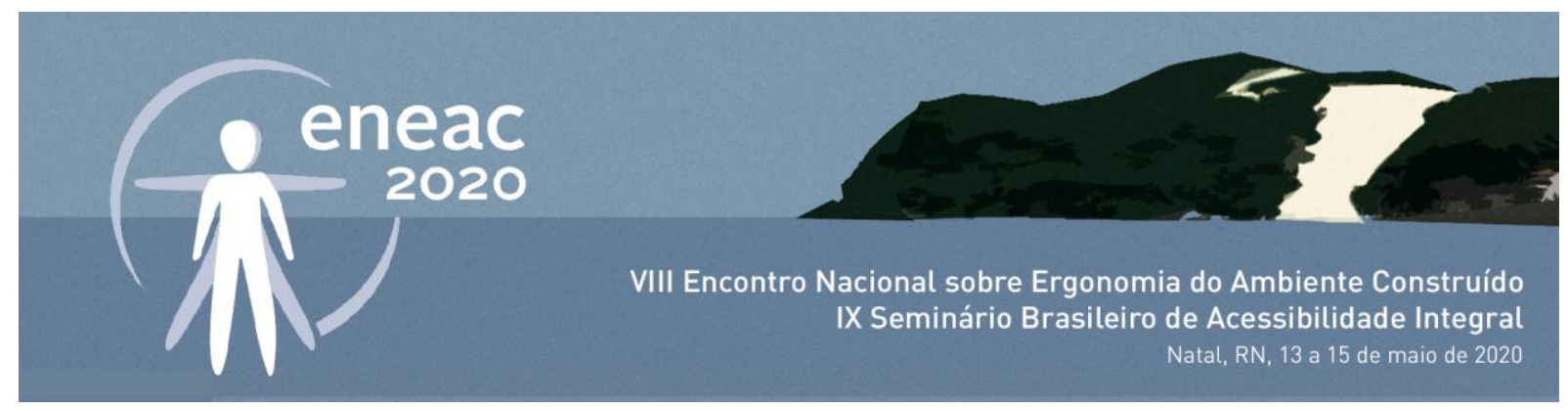

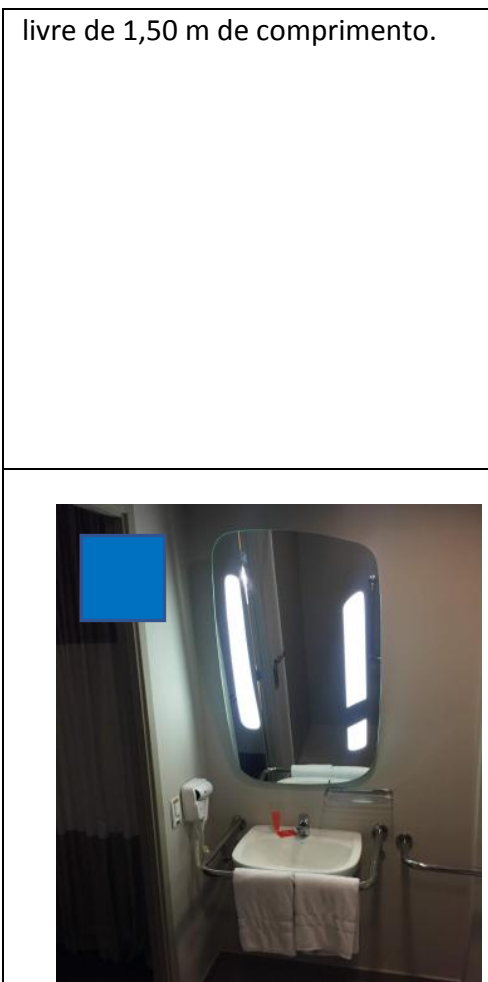

Pia com $0,80 \mathrm{~m}$ de altura e torneira de pressão. Uso de barra de apoio ao redor da cuba não mais recomendada pela NBR 9050. Utensílios como saboneteira e papeleira com altura superior à mínima de $0,80 \mathrm{~m}$ de altura. Espelho com altura inferior superior à $0,90 \mathrm{~m}$

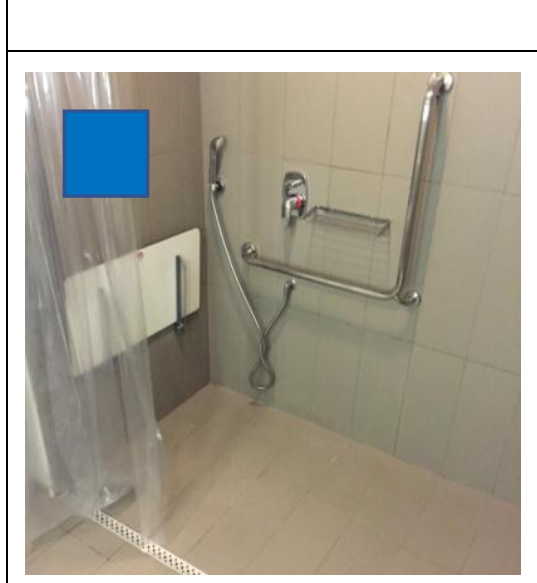

No boxe de chuveiro há área de transferência externa ao boxe, que permite aproximação e entrada de cadeira de rodas.

Existência de ralo nivelado ao piso. Existe banco articulado com superfície

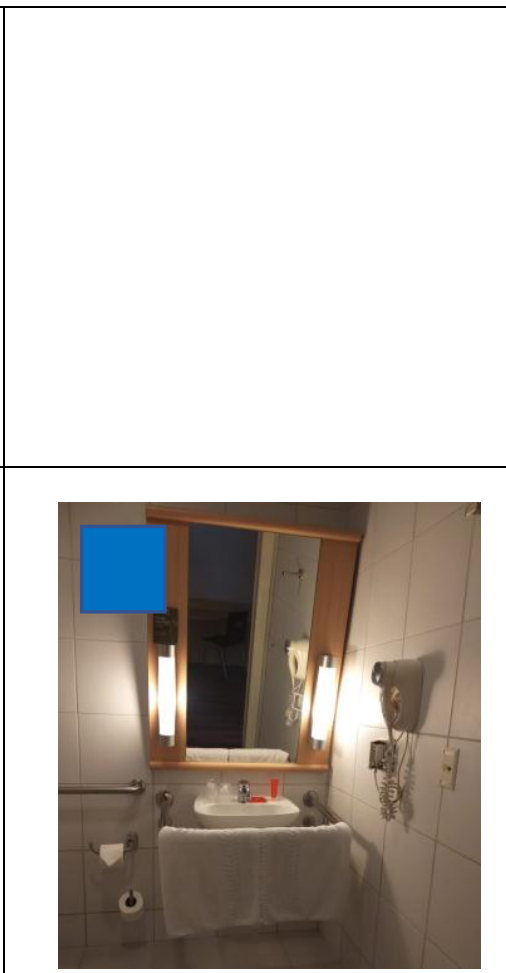

Pia com $0,80 \mathrm{~m}$ de altura e torneira de pressão. Uso de barra de apoio ao redor da cuba não mais recomendada pela NBR 9050. Utensílios como saboneteira e papeleira com altura superior à mínima de $0,80 \mathrm{~m}$.

Espelho com altura inferior superior à $0,90 \mathrm{~m}$.

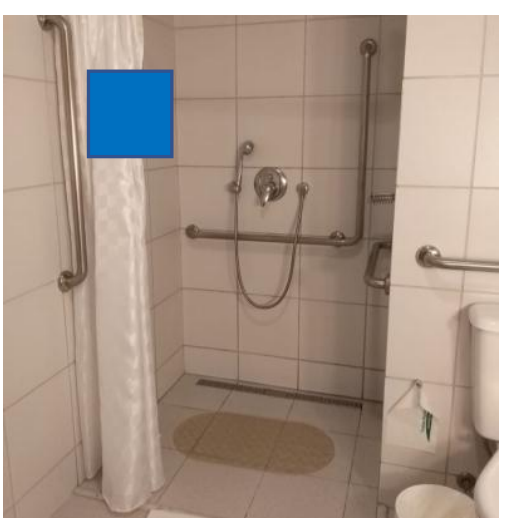

No boxe de chuveiro há área de transferência externa ao boxe, que permite aproximação e entrada de cadeira de rodas. Existência de ralo nivelado ao piso. Não há banco articulado. perpendicular e diagonal para a bacia sanitária. A Norma 9050 sugere não utilizar bacia nem assento com abertura frontal. No caso de existir parede lateral junto à bacia sanitária, deve haver barras para apoio e transferência: uma instalada horizontalmente na parede de fundos; e duas na parede lateral, sendo uma instalada horizontalmente e outra verticalmente.

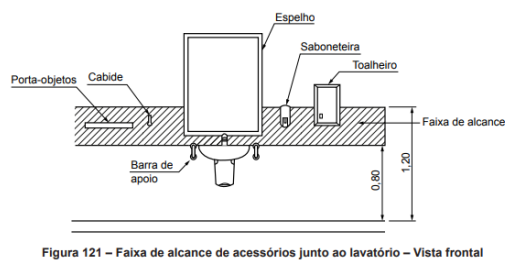

Os acessórios do sanitário, tais como toalheiro, cabide, porta-objetos, saboneteira, etc., devem estar localizados dentro da faixa de alcance confortável, a uma altura entre $0,80 \mathrm{~m}$ e $1,20 \mathrm{~m}$ do piso. 0 espelho deve esta instalado até $1,80 \mathrm{~m}$ do piso, sendo a altura máxima da sua borda inferior de $0,90 \mathrm{~m}$.

No boxe de chuveiro, deve ser prevista área de transferência externa ao boxe, de forma a permitir a aproximação e entrada de cadeira de rodas, cadeiras de banho ou similar. É necessário que o boxe de chuveiro seja provido de banco articulado ou removível, com cantos arredondados e superfície antiderrapante impermeável.

No boxe de chuveiro as barras de apoio devem estar posicionadas nas paredes lateral e do fundo do banco. A barra de apoio ao fundo do banco deve estar posicionada verticalmente, possuindo comprimento mínimo de $0,70 \mathrm{~m}$ e sua borda inferior está a $0,75 \mathrm{~m}$ do piso. A NBR 9050 também sugere barra de apoio em " $\mathrm{L}$ " ou duas barras de apoio (uma instalada horizontalmente e 


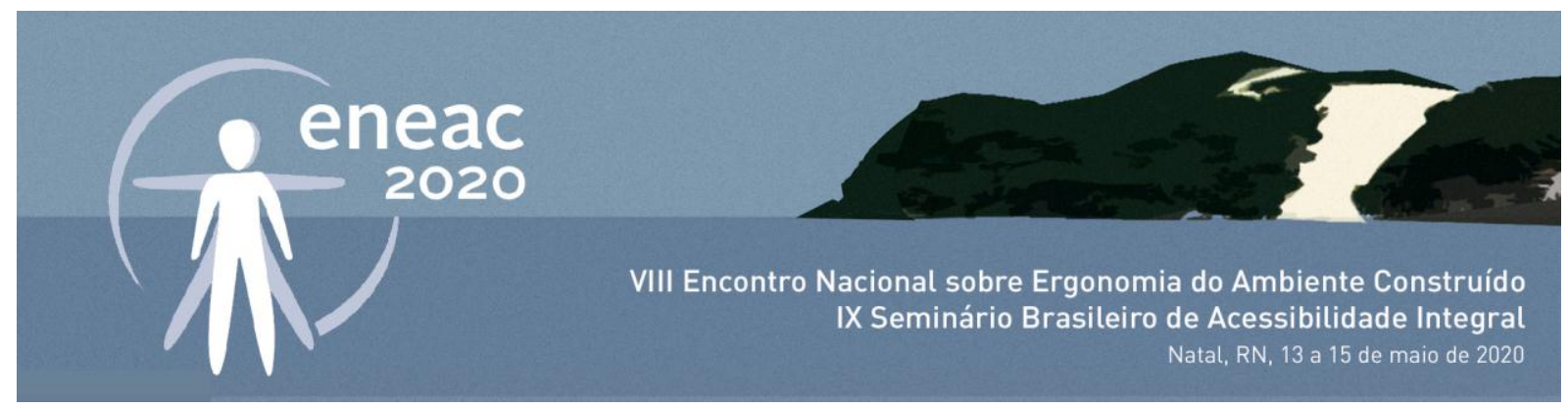

\begin{tabular}{|l|l|l|}
\hline $\begin{array}{l}\text { antiderrapante, porém sem barra de } \\
\text { apoio na parede no fundo do banco. } \\
\begin{array}{l}\text { Existência de barra em "L" na parede } \\
\text { lateral ao banco. }\end{array}\end{array}$ & $\begin{array}{l}\text { Existência de barra em "L", e barra } \\
\text { vertical de apoio na entrada do box. }\end{array}$ & $\begin{array}{l}\text { outra a 90) na parede lateral ao } \\
\text { banco. }\end{array}$ \\
\hline Fonte: Fotos autores &
\end{tabular}

Interessante ressaltar no Hotel E em Miraflores - Lima é a apresentação no elevador de um quadro com os andares com suítes acessíveis (Figuras 6 e 7).

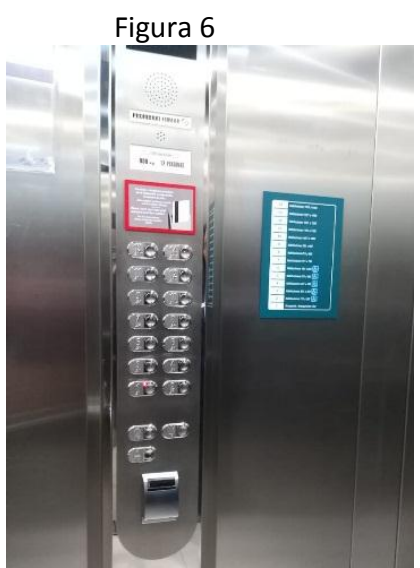

Fonte: Foto autores

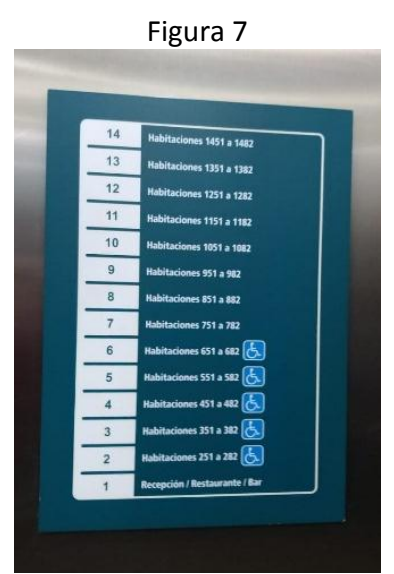

Fonte: Foto autores

No que se refere às circulações horizontais e verticais, ambos os hotéis apresentam resultados satisfatórios na largura de seus corredores, qualidade do piso, contraste de cores entre parede, piso e móveis, linha-guia edificada, dimensões de elevadores, etc. Esses são elementos que, quando em conformidade com a NBR 9050/2015, compõem rotas acessíveis, porém, tanto no Hotel B de Fortaleza quanto no de Lima, a sinalização visual e tátil ocorre nos elevadores, conduto nos demais espaços, deixa a desejar, induzindo às pessoas com deficiência visual a se deslocarem procurando os limites edificados, que nem sempre estão livres.

\section{Considerações Finais}

Levando em consideração os parâmetros analisados - passeios; estacionamento aberto ao público; acesso à edificação; balcão de recepção; sala de estar e espera; banheiros; restaurante e suíte acessível, constatamos muita semelhança nas condições de atendimento de ambos hotéis nos quesitos de acessibilidade, ressaltando que a maioria dos critérios de avaliação foram positivamente contemplados.

Um aspecto importante da análise desses hotéis é evidenciado no critério do acesso, onde é encontrado o maior contraste de resultados. O entorno do Hotel E de Miraflores-Lima oferece qualidade ao usuário ao apresentar faixa de pedestres, guias rebaixadas, faixa livre contínua e piso tátil direcional, o que vai de encontro à realidade do entorno do Hotel B Fortaleza, onde não há faixa de pedestres e guias rebaixadas, além de acentuada inclinação do passeio devido entrada para carros não ter sido feita de acordo com a NBR 9050/2015. 


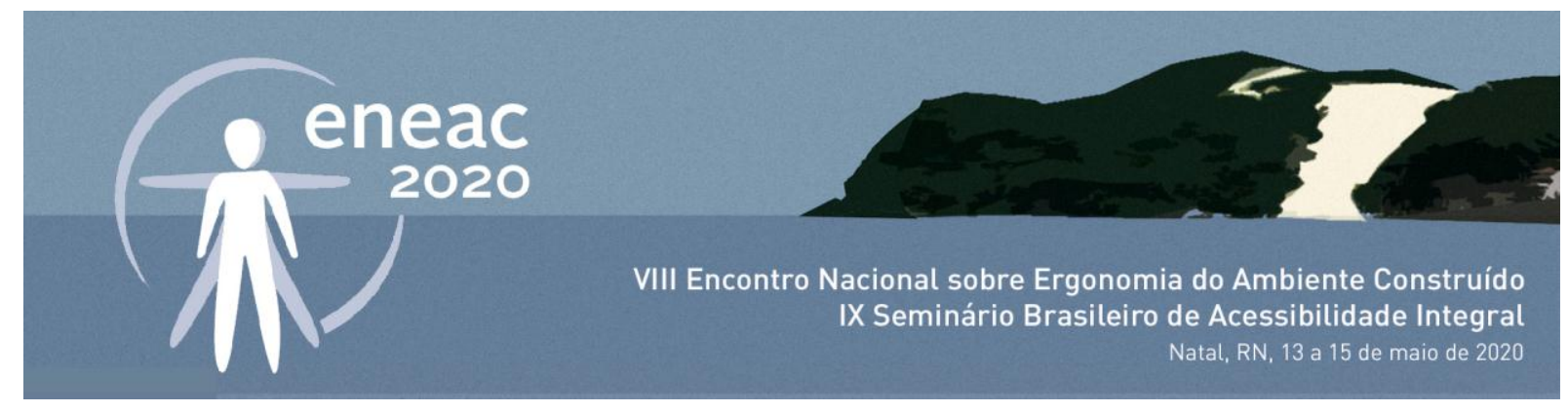

Ainda, ao analisar ambas as suítes acessíveis, fica evidente a qualidade das instalações por atenderem diversos requisitos das normas vigentes. Porém, mesmo no caso dos banheiros em ambas suítes acessíveis dos hotéis, que atendem à norma anterior, necessitando de atualização, não impedem, contudo, o uso por pessoas com deficiência ou mobilidade reduzida.

Enfim, a pesquisa demonstra até aqui, que a rede hoteleira, no que se refere aos hotéis visitados, tem a iniciativa de incorporar em sua gestão e espaço físico as questões relativas à acessibilidade para atender melhor a diversidade de público. Como recomendação diante da análise comparativa, seria sugerir a adoção, por parte do hotel no Brasil, da sinalização utilizada nas circulações e no elevador, indicando os andares e a localização da suíte acessível, o que facilita a orientação do usuário como se apresenta no hotel de Lima.

\section{AGRADECIMENTOS}

Nossos agradecimentos ao CNPq e FUNCAP pelo auxílio financeiro de cotas de Iniciação Científica em forma de bolsa ao Programa Institucional de Bolsas de Iniciação Científica PIBIC/UFC.

\section{REFERÊNCIAS}

ALEXANDRE, Dora Maria Messias. O Turismo para Todos na oferta hoteleira de Lisboa: um custo ou um investimento? Dissertação de Mestrado em Turismo. Escola Superior de Hotelaria e Turismo do Estoril - Portugal. 2013.

ASSOCIAÇÃO BRASILEIRA DE NORMAS TÉCNICAS. NBR 9050: Acessibilidade na edificações, mobiliário, espaços e equipamentos urbanos. Rio de Janeiro: ABNT, 2015.

BRASIL. Decreto n. 5.296/2004. de 2 de dezembro de 2004. Regulamenta as Leis nos 10.048, de 8 de novembro de 2000, que dá prioridade de atendimento às pessoas que especifica, e 10.098, de 19 de dezembro de 2000, que estabelece normas gerais e critérios básicos para a promoção da acessibilidade das pessoas portadoras de deficiência ou com mobilidade reduzida, e dá outras providências.

BRASIL. Lei no 13.146, de 6 de julho de 2015. Institui a Lei Brasileira de Inclusão da Pessoa com Deficiência (Estatuto da Pessoa com Deficiência). Disponível em: http://www.planalto.gov.br/ccivil_03/_ato2015-2018/2015/lei/l13146.htm. Acesso em: maio 2017.

BRASIL. Ministério de Turismo. Secretaria de direitos Humanos. Estudo do Perfil de Turistas - Pessoas com Deficiência. Documento Técnico - 2013.

BRASIL. Ministério do Turismo-MTur. Instituto Brasileiro de Turismo. Plano Nacional de Turismo 2013-2016.

BRASIL. Ministério do Turismo. Plano Nacional de Turismo (PNT) 2018-2022. Brasília, DF. 2018.

CAMBIAGHI, S. Desenho Universal: métodos e técnicas para arquitetos e urbanistas. São Paulo: Ed. Senac São Paulo, 2007.

DISCHINGER, M.; BINS ELY, V. H. M.; PIARDI, S. M. D. G. Promovendo a acessibilidade espacial nos edifícios públicos: Programa de acessibilidade às pessoas com deficiência ou mobilidade reduzida nas edificações de uso público. 01. ed. Florianópolis: MPSC, 2012. 135p.

FORTALEZA. Lei № 10668 DE 02/01/2018, consolida a legislação municipal de Fortaleza e dispõe sobre o Estatuto Municipal da Pessoa com Deficiência.

LEITE, Y. V. P.; LUCENA, E. DE A. Mudanças Estratégicas da Accor Hotels do Brasil. Revista Base (Administração e Contabilidade) da UNISINOS, vol. 6, núm. 2, mayo-agosto, pp. 152-168. Universidade do Vale do Rio dos Sinos. São Leopoldo, Brasil, 2009.

ORNSTEIN, Sheila; ROMÉRO, Marcelo. Avaliação Pós-Ocupação do Ambiente Construído. São Paulo: Nobel, 1992.

Preiser, W., OSTROFF, E. (eds.). Universal Design Handbook. New York: McGrraw Hill, 2001. 1216p.

RHEINGANTZ, Paulo Afonso... [et al.]. Observando a qualidade do lugar: procedimentos para a avaliação pós-ocupação -- 


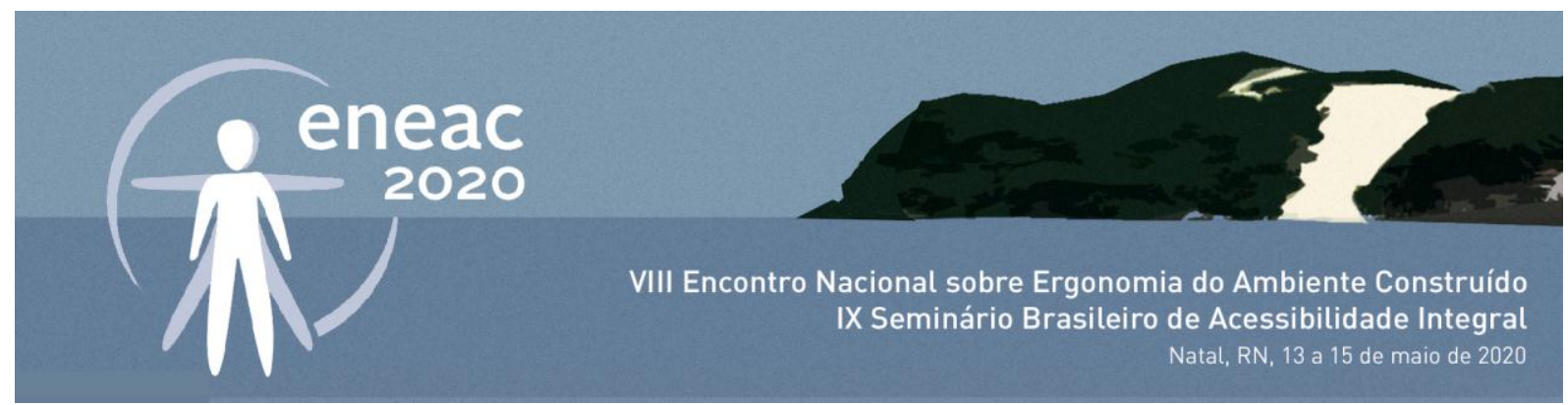

Rio de Janeiro : Universidade Federal do Rio de Janeiro, Faculdade de Arquitetura e Urbanismo, Pós- Graduação em Arquitetura, 2009. 117 p. : il. color. ; 21 cm. - (Coleção PROARQ)

SANTIAGO, Z. M. P.; SANTIAGO, C. Q. de; SOARES, T. S. Acessibilidade no espaço público: o caso das praças de Fortaleza. In: Revista Ergodesign \& HCl, número 2. Vol. 4. ISSN 2317-8876. Rio de Janeiro: PUC-Rio. Departamento de Artes \&Design/ PPGDesign. LEVI, 2016.

SILVA, S. C.; MORANO, R. P.; SANTIAGO, Z. M. P.; Villarouco, V. Hostel: uma forma de Hospitalidade Aberta, p. 517-533. In: Anais do 170 Congresso Internacional de Ergonomia e Usabilidade de Interfaces Humano-Tecnologia e o 17 ㅇ Congresso Internacional de Ergonomia e Usabilidade de Interfaces e Interação Humano-Computador. São Paulo: Blucher, 2019. ISSN 2318-6968, DOI 10.5151/ergodesign2019-2.37.

SOUZA, Marilena Carvalho de. Os hotéis e a cidade: o caso de Fortaleza. Dissertação Mestrado em Arquitetura e Urbanismo. Universidade Presbiteriana Mackenzie, São Paulo, 2015.

VANZELLA, Elídio; BRAMBILLA, Adriana, DA SILVA, Marcia Félix. (Org.). T\&H. Turismo e Hotelaria no contexto da acessibilidade. João Pessoa: Editora do CCTA, 2018. 289p. ISBN: 978-85-9559-066-3

VARGAS, Heliana Comin \& PAIVA, Ricardo Alexandre (orgs.). Turismo, Arquitetura e Cidade - 1a ed. Série Intervenções Urbanas. Coleção intervenções Urbanas. São Paulo: Ed. Manole, 2016.

VIEIRA, Rodrigo. Turismo responde por 8,1\% do PIB Brasil; veja dados globais. Disponível em: https://www.panrotas.com.br/mercado/economia-e-politica/2019/03/turismo-responde-por-81-do-pib-brasil-vejadados-globais_162774.html. Acesso em 30/01/2020.

Sites

https://ibis.accor.com/pt-br/world/hoteis-ibis-monde.shtml

https://www.incluyeme.com/todo-lo-que-necesitas-saber-sobre-la-ley-n29973-para-personas-con-discapacidad-en-peru/

\footnotetext{
' Os nomes originais dos hotéis serão preservados neste trabalho.
} 